\title{
Analysis of Increasing D-Dimer, Decreasing P/F Ratio and Rox Index As Predictors Of HFNC Therapy Failure In Covid-19 Patients
}

\author{
Andi Emier Hidayat Arsan ${ }^{\mathrm{a}}$, Edward Kusuma ${ }^{\mathrm{a}}$, Kun Arifi Abbas ${ }^{\mathrm{a}}, \mathrm{Hamzah}^{\mathrm{a}}$, Christrijogo Sumartono ${ }^{\mathrm{a}}$ \\ a Department of Anesthesiology and Reanimation, Faculty of Medicine, Universitas Airlangga, Surabaya, 60286, \\ Indonesia \\ *Corresponding Author: edu@anestesi-surabaya.com
}

\begin{abstract}
Patients with severe symptoms of COVID-19 have an ARDS. HFNC is one of the therapies to treat ARDS in COVID-19. The aim of this study is to analyse the relationship between increased D-Dimer, decreased P/F Ratio and ROX Index with failure of HFNC therapy. This study was an observational, retrospective analytic study with total sampling technique. Ethical clearance was issued by the Ethics Committee of RSUD Dr. Soetomo Surabaya. The study was conducted in the COVID-19 isolation room from June until December 2020. The inclusion criteria were confirmed COVID-19 patients, aged 17-64 years with ARDS symptoms and requiring HFNC. D-dimer, P/F Ratio and ROX Index were observed on day 0 and day 3. The patient was followed while in COVID-19 Isolation Room-1 Dr Soetomo Hospital until discharged from isolation room or need a mechanical ventilation. A total of 87 research subjects were included in this study, and 72 research subjects were further assessed on the 3rd day. The decrease in ROX Index was associated with the incidence of HFNC failure (H-0 p=0.020 and H-3 p $<0.001)$. The relative risk of HFNC failure in the ROX Index $<3.85$ group on day 0 was 2.4 times and on day 3 was 5.1 times. The increase in D-Dimer was associated with the incidence of HFNC failure (H-0 p=0.023 and H-3 p< 0.001). The relative risk of HFNC failure in the group with D-Dimer $>1,360 \mathrm{mcg} / \mathrm{l}$ on day 0 was 2.1 times, while in the group with D-Dimer $>2,135 \mathrm{mcg} / \mathrm{l}$ on day 3 was 6.2 times. The decrease in the PF ratio was associated with the incidence of HFNC failure $(\mathrm{H}-0 \mathrm{p}=0.011$ and $\mathrm{H}-3 \mathrm{p}<0.001)$. The relative risk of HFNC failure in the group with $\mathrm{PF}$ ratio $<119 \mathrm{mmHg}$ on day 0 was 2.3 times, while in the group with $\mathrm{PF}$ ratio $<110.5 \mathrm{mmHg}$ on day 3 it was 9.0 times. There was a significant and strong relationship between increased D-Dimer levels, decreased $\mathrm{PF}$ ratio, and decreased ROX Index with the incidence of HFNC failure in the COVID-19 Isolation Room of RSUD Dr Soetomo.
\end{abstract}

Keywords : D-dimer, ROX index, P/F Ratio, HFNC failure, COVID-19, ARDS

\section{Introduction}

COVID-19, the emerging infectious disease caused by SARS-COV-2 infection, could manifest ad asymptomatic, mild symptoms, until severe and critical form. Half of these patients experienced dyspnoea in a week. In severe and critical clinical manifestation, progressive deterioration like acute respiratory distress syndrome (ARDS) could occur and leads to hypoxia and mortality. these patients need intensive care in ICU and may need mechanical ventilatory support for maintaining respiratory functions.(1)

Hypoxia stimulate the increase of HIF-1 (hypoxia inducible factor-1) expression, which is inversely proportionated to protein S synthesis by Liver.(2) Protein S plays an important role in direct anticoagulation that inhibit prothrombin. Inhibition of protein $\mathrm{S}$ synthesis leads to the increase of prothrombin, followed by thrombin generation by the help of vitamin K. Furthermore, this vicious cycle of sepsis-coagulopathy-hypoxia occurs.(2) Cytokine storm that leads to ARDS and hypoxia become a strong hypothesis of vascular thrombosis and microangiopathy generation. A high concentration of D-dimer reflects the presence of vascular thrombosis. Low D-dimer concentration results to a lower mortality rate and a better prognosis.(3)

ARDS, a condition that often-complicating COVID-19, was defined as the acute reaction of hypoxemia (partial arterial pressure in Oxygen fraction at inspiration $\mathrm{PaO} 2 / \mathrm{FIO} 2 \leq 200 \mathrm{mmHg}$ ) and was concomitant with bilateral infiltrate shown in radiographic X-ray, without the evidence of left atrial hypertension and Acute Lung Injury (ALI) with similar definition but with a $\mathrm{PaO} 2 / \mathrm{FIO} 2$ of $\leq 300 \mathrm{mmHg}$.(4)

High Flow Nasal Cannula (HFNC) therapy is a respiratory support alternative that is commonly used for hypoxemic COVID-19 patients. Some parameters had been developed to measure HFNC effectivity and to measure its failure to support the respiratory progression of COVID-19 patients. Hypoxia caused by ARDS was 
because of the cytokine storm phenomenon that was alongside with disease severity and hypercoagulation marked by the increase of D-dimer, thus causing HFNC therapy failure. In COVID-19 pneumonia, application of ROX index was also useful. A study from Italy reported that ROX index upon admission in emergency department could predict hospitalization, and mortality in 30rd day. ROX index, laboratory parameters, imaging, and clinical condition of the patients were significantly correlated with the need of mechanical ventilation and predicting HFNC therapy failure.(5) In Indonesia, ROX index was also useful and recommended for HFNC failure prediction among COVID-19 patients.(6) ROX index formula was calculated by dividing $\mathrm{SpO} 2(\%)$ / $\mathrm{FiO} 2(\%)$ to respiratory rate (times/minute). The numerators were the variables correlated with HFNC therapy success, and the denominator was the variables correlated to the HFNC therapy failure. In a non-COVID-19 population, ROX index of $>4,88$ in 2, 6, or 12 hours after HFNC, was significantly correlated with a lower endotracheal tube intubation risk. ROX index of less than 3,85 after 12 hours of HFNC therapy was a predictor of HFNC therapy failure.(7) We aimed to analyse the association of D-dimer concentration, P/F ratio, and ROX index towards HFNC therapy failure in COVID-19 patients with ARDS.

\section{Methods}

\subsection{Study Design}

This study was an observational analytical study with a retrospective design. This study was taken place in isolation room ICU of DR. Soetomo general Hospital, Surabaya, Indonesia. We analysed the association of Ddimer concentration, P/F ratio, and ROX index and HFNC therapy failure in all COVID-19 patients with ARDS, using medical record and patients record form in ICU.

2.2 Study Population

The inclusion criteria were the COVID-19 patients aged 17-64 years old admitted to isolation room COVID-19 ICU who had the ARDS symptoms and used HFNC therapy. We exclude the pregnant women and patients with anticoagulation history which was not correlated with COVID-19 therapy. A consecutive sampling was performed to include the total patients who met inclusion criteria from the period of June- December 2020.

\subsection{Variables and Outcomes}

Independent variables were plasma D-dimer concentration, P/F ratio, ROX index, with the study outcome of HFNC failure. HFNC failure was defined as the presence of these following condition while on HFNC therapy: decrease of consciousness, respiratory rate $>30$ times per minute, $\mathrm{SpO} 2<92 \%$, respiratory muscle use, pulse rate of > 120 times per minute, and in COVID-19 with HFNC flow of 60lpm with FiO2 100\%, the evaluation was performed for each hour. D-Dimer concentration in plasma was measured using latex enhance turbidimetric test with coagulometer sysmex CA-1500. The normal value used for plasma D-dimer was $<500 \mathrm{ng} / \mathrm{ml}$. P/F ratio was calculated by dividing the Oxygen arterial pressure $(\mathrm{PaO} 2)$ by Oxygen fraction $(\mathrm{FiO} 2)$ and was commonly used to measure the presence of hypoxemia. ROX index formula was calculated by dividing $\mathrm{SpO} 2(\%) / \mathrm{FiO} 2(\%)$ to respiratory rate (times/minute).

\subsection{Statistical analysis}

Data was analysed using SPSS 24.0 and presented with tables and graphs. Correlation of the alteration of D-dimer concentration, P/F Ratio and Rox index HFNC therapy failure used Spearman Correlation (r) test.

\section{Results}

\subsection{Baseline characteristics}

A total of 87 patients was eligible for this study, with the age range of 24 to 76 years old. The average of the age distribution was 51 years old. Male was dominated the study population $54(62.1 \%)$ and female in 33 patients (37.9\%). Comorbidities presented in 72 out of 87 patients, with the most prevalent comorbidity was Diabetes Mellitus in 41 patients $(47.1 \%)$. (Table 1$)$ 
Table 1. Baseline characteristics of the subjects

\begin{tabular}{|c|c|c|}
\hline \multicolumn{2}{|c|}{ Variables } & N (Sum) / Median \\
\hline Gender & 33 & $37.9 \%$ \\
\hline Female & 54 & $62.1 \%$ \\
\hline Male & 51,0 years old & 19 \\
\hline Age & 41 & $47,1 \%$ \\
\hline Comorbidities & 32 & $36,8 \%$ \\
\hline Diabetes Mellitus & 19 & $21,8 \%$ \\
\hline Hypertension & 11 & $12,6 \%$ \\
\hline Obesity & 10 & $11,5 \%$ \\
\hline Hepatitis & 6 & $6,9 \%$ \\
\hline Chronic heart disease & 3 & $3,4 \%$ \\
\hline Renal Impairment & 3 & $3,4 \%$ \\
\hline Asthma & 2 & $2,3 \%$ \\
\hline Allergic & 2 & $2,3 \%$ \\
\hline Pulmonary tuberculosis & 7 & $8,0 \%$ \\
\hline Stroke & 15 & $17,2 \%$ \\
\hline Other comorbidities & 28 & $32,2 \%$ \\
\hline Without comorbidity & & \\
\hline
\end{tabular}

3.2 Baseline values of the D-dimer concentration, P/F Ratio and ROX index of the study population In our study, the independent variables were measured at day- 0 and day-3. If there was a clinical deterioration or HFNC failure or mortality before day-3, those subjects were not included on the next analysis. At day-0, there were a total of 86 patients while at day- 3 there was a total of 66 patients included in the analysis.

Table 2. Baseline Value of the Independent Variables

\begin{tabular}{|c|c|c|c|}
\hline D-Dimer & Range & Median & IQR \\
\hline Day-0 & $217-35.200$ & 1.335 & 2.377 \\
\hline Day-3 & $190-11.760$ & 1.420 & 1.480 \\
\hline P/F Ratio & Range & Median & IQR \\
\hline Day-0 & $54-220$ & 141 & 105 \\
\hline Day-3 & $51-366$ & 197 & 103 \\
\hline Rox Index & Range & Median & IQR \\
\hline Day-0 & $1,8-16,33$ & 5,89 & 3,96 \\
\hline Day-3 & $2,4-16,00$ & 6,61 & 4,94 \\
\hline
\end{tabular}

3.3 Correlation of decreasing ROX index with HFNC Failure Incidence

At day-0, as many as 13 out of 87 subjects $(15,1 \%)$ had ROX index of less than 3,85 points. HFNC failure incidence in patients with ROX index of $<3,85$ points were 8 out of 87 subjects $(9,3 \%)$. Whereas HFNC failure in patients with $\mathrm{ROX}>3,85$ were 19 from 87 subjects $(22,1 \%)$. A significant correlation was found between ROX index at day-0 with HFNC failure during ICU stay $(\mathrm{p}=0,020)$.(Table 3 )

Patients with ROX index $<3,85$ at day-0 had a relative risk (RR) of 2,4 (1,3-4,2) times higher compared to ROX index $>3,85$ towards HFNC failure incidence. Sensitivity, specificity, positive predictive value, dan negative predictive value of ROX index at day-0 were $29,6 \%, 91,5 \%, 61,5 \%$, and 74,0\%, respectively.

ROX index at day-3 and HFNC failure incidence were significantly correlated ( $<<0,001$ ), with RR of 5,1 $(2,7-9,4)$ compared to those with ROX index of $>3,85$. Sensitivity, specificity, positive predictive value, dan negative predictive value of ROX index at day-3 were $35,3 \%, 98,2 \%, 85,7 \%$, and 83,1\% respectively. 
Table 3. Correlation of ROX Index at day-0 and day-3 towards HFNC incidence during ICU stay

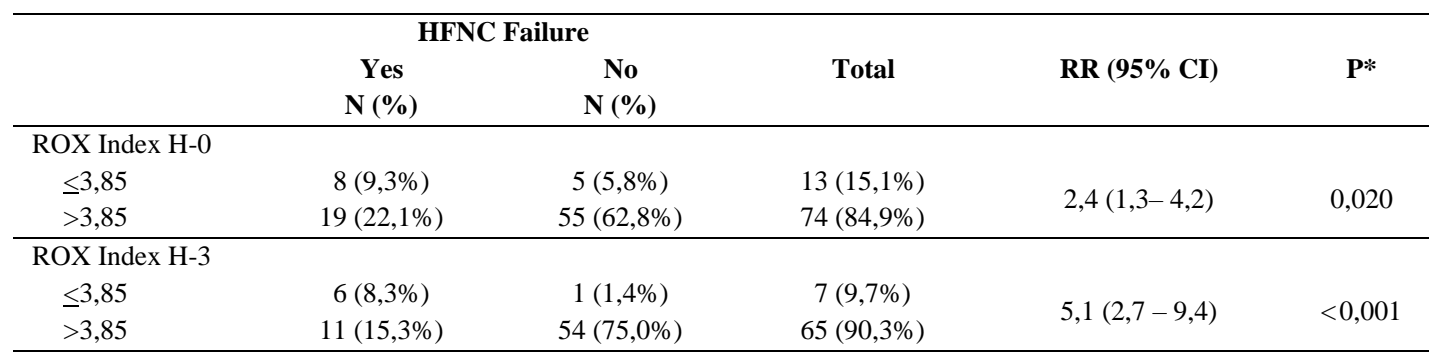

3.4 Correlation of increasing D-Dimer with HFNC Failure Incidence

ROC curve was generated to find the cut-off value of D-Dimer concentration at day- 0 and day- 3 towards HFNC failure incidence during ICU stay. Plasma D-dimer cut-off at day-0 was $1.360 \mathrm{mcg} / \mathrm{l}$ and $2.135 \mathrm{mcg} / \mathrm{l}$ at day-3.(Figure 1)


Fig.1. ROC Curve of D-Dimer concentration at (A) day-0 and (B) day-3 of ICU stay

Patients with D-Dimer $>1.360 \mathrm{mcg} / \mathrm{l}$ at day-0 had a relative risk of developing HFNC for 2,1 $(1,1-4,1)$ times greater compared to those with D-Dimer $<1.360 \mathrm{mcg} / \mathrm{l}$. Sensitivity, specificity, positive predictive value, dan negative predictive value of D-dimer at day- 0 were $64,3 \%, 62,7 \%, 45,0 \%$, and $78,7 \%$, respectively. A significant correlation was found in D-dimer concentration at day- 0 towards HFNC failure incidence $(\mathrm{p}=$ 0,023). (Table 4)

Table 4. Correlation of D-dimer at day-0 and day-3 towards HFNC incidence during ICU stay

\begin{tabular}{|c|c|c|c|c|c|}
\hline & \multicolumn{2}{|c|}{ HFNC Failure } & \multirow[b]{2}{*}{ Total } & \multirow[b]{2}{*}{ RR $(95 \%$ CI) } & \multirow[b]{2}{*}{ P* } \\
\hline & $\begin{array}{c}\text { Yes } \\
\mathbf{N}(\%)\end{array}$ & $\begin{array}{c}\text { No } \\
\mathbf{N}(\%)\end{array}$ & & & \\
\hline \multicolumn{6}{|c|}{$\begin{array}{l}\text { D-Dimer H-0 } \\
(\mathrm{mcg} / \mathrm{l})\end{array}$} \\
\hline$\geq 1.360$ & $18(20,7 \%)$ & $22(25,3 \%)$ & $40(46,0 \%)$ & \multirow{2}{*}{$2,1(1,1-4,0)$} & \multirow{2}{*}{0,023} \\
\hline$-\overline{<} 1.360$ & $10(11,5 \%)$ & $37(42,5 \%)$ & $47(54,0 \%)$ & & \\
\hline \multicolumn{6}{|c|}{$\begin{array}{l}\text { D-Dimer H-3 } \\
(\mathrm{mcg} / \mathrm{l})\end{array}$} \\
\hline$\geq 2.135$ & $14(18,9 \%)$ & $9(12,2 \%)$ & $23(31,1 \%)$ & \multirow{2}{*}{$6,2(2,5-15,2)$} & \multirow{2}{*}{$<0,001$} \\
\hline$<2.135$ & $5(6,8 \%)$ & $44(62,2 \%)$ & $49(68,9 \%)$ & & \\
\hline
\end{tabular}


There was a significant correlation of D-dimer concentration at day-3 towards HFNC failure during ICU stay ( $\mathrm{p}<0,001)$. (Table 4) Patients with D-dimer concentration of $>2.135 \mathrm{mcg} / \mathrm{l}$ at day-3 had a RR of 6,2 (2,5 15,2). Sensitivity, specificity, positive predictive value, dan negative predictive value of $\mathrm{D}$-dimer concentration at day-3 towards HFNC incidence during ICU stay were 73,7\%, 83,6\%, 60,9\%, and 83,6\%, respectively.

3.5 Correlation of decreasing P/F Ratio with HFNC Failure Incidence ROC curve was generated to find the cut-off value of $\mathrm{P} / \mathrm{F}$ ratio at day- 0 and day-3 towards HFNC failure incidence during ICU stay. Cut-off value of $\mathrm{P} / \mathrm{F}$ ratio at day-0 was $119 \mathrm{mmHg}$ and110,5 $\mathrm{mmHg}$ at day-3.
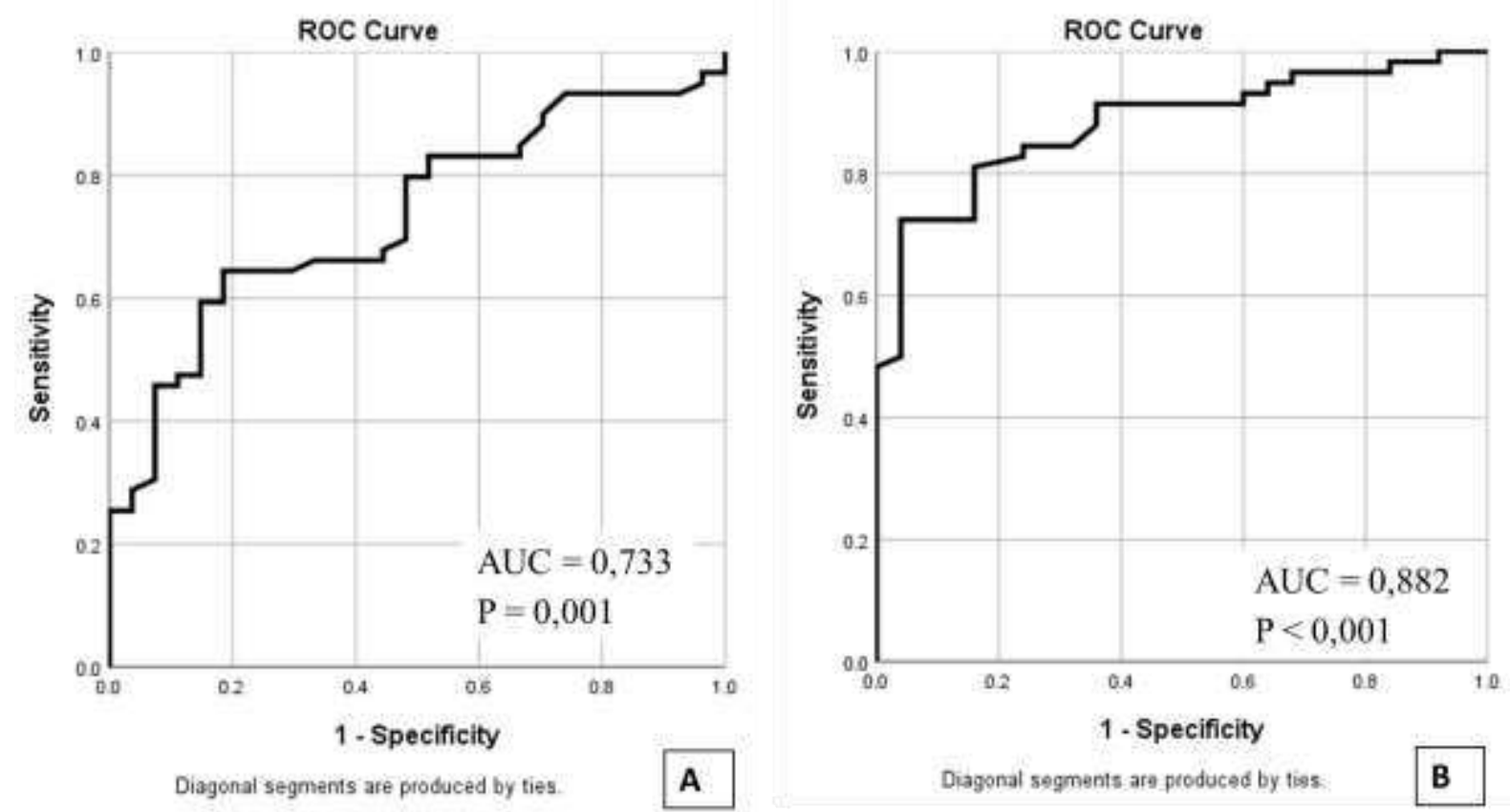

Fig. 2. ROC Curve of P/F Ratio at (A) day-0 and (B) day-3 of ICU stay

Significant correlation was demonstrated between $\mathrm{P} / \mathrm{F}$ ratio at day- 0 as well as at day-3 and HFNC failure during ICU stay $(\mathrm{p}=0,011$ ) (Table 5). Patients with $\mathrm{P} / \mathrm{F}$ ratio $<119,0 \mathrm{mmHg}$ at day-0 had RR of $2,3(1,2-4,4)$. Sensitivity, specificity, positive predictive value, dan negative predictive value of P/F ratio at day- 0 were: $64,3 \%$, $66,1 \%, 47,4 \%$, and $79,6 \%$ respectively.

At day-3, P/F ratio was also correlated significantly $(\mathrm{p}<0,001)$ with the RR of patients with $\mathrm{P} / \mathrm{F}$ ratio $<110,5$ $\mathrm{mmHg}$ was $9,0(2,9-28,4)$ compared to those whose $\mathrm{P} / \mathrm{F}$ ratio $>110,5 \mathrm{mmHg}$. Sensitivity, specificity, positive predictive value, dan negative predictive value of $\mathrm{P} / \mathrm{F}$ ratio at day-3 towards HFNC incidence during ICU stay were: $83,3 \%, 80,0 \%, 57,7 \%$, and $93,6 \%$, respectively.

\section{Discussion}

COVID-19 with ARDS needed an advanced oxygen supplementation like using HFNC. Early non-invasive Oxygen supplementation (like HFNC) was proved to reduce the need of intensive care unit and mechanical ventilator use in this time of COVID-19 crisis.(8) in our study, we identified the characteristics of ARDS COVID-19 patients taken care in isolation ICU in our centre, and found that the median age was 51 years old, and with the most frequent comorbidity of Diabetes mellitus. A similar study in Korea showed that COVID19 with the advancing age had a greater risk of mortality and greater risk of needing Oxygen supplementation using HFNC or mechanical ventilation.(9)

Mortality in COVID-19 patients was also correlated with the presenting comorbidities. A meta-analysis of the prior studies stated that there was a strong correlation between Diabetes mellitus and COVID-19 severity OR 2,75 (95\% CI: 2,09-3,62; p<0,01).(10) 
D- dimer concentration could reflect the presenting thrombosis at the lungs. The higher the D-dimer concentration, the higher risk of thrombosis inside lungs' vascular. Thrombus will subsequently impair gas exchange and correlated with respiratory failure degree. Severe respiratory failure may leads to HFNC failure and the need of invasive ventilation. A study in India investigated that $32 \%$ of patients with HFNC needed to be transferred to ICU for NIV or invasive ventilation, which were the signs of HFNC failure. Patients with HFNC failure had a median D-dimer concentration that was higher compared to those whom without HFNC failure $(2,2 \mathrm{mcg} / \mathrm{ml} v \mathrm{vs} 0,6 \mathrm{mcg} / \mathrm{ml} ; \mathrm{p}=0,001)$. D-dimer as the biomarker of inflammation was found to be increased in severe COVID-19 pneumonia. D-dimer increase was correlated with respiratory function and was determined as the predictor of mortality in COVID-19 patients with ARDS. A prior study showed a D-dimer cut-off of $>1,7 \mathrm{mg} / \mathrm{l}$ to predict $87 \%$ of HFNC failure. This cut-off could stratify COVID-19 patients with ARDS as those who had a greater risk of developing HFNC failure and need to be transferred immediately to ICU.(11) whereas our study showed the D-dimer cut-off of $1.360 \mathrm{mcg} / \mathrm{l}$ at day- 0 and $2.135 \mathrm{mcg} / \mathrm{l}$ at day- 3 . Compared to day-0, D-dimer cut-off at day-3 had greater prediction values.

Compared to the ROX index, for predicting HFNC failure incidence, D-dimer had a higher sensitivity, but less specificity. P/F ratio, a simple parameter on identifying respiratory failure specifically for ARDS, and become an independent risk factor of 30-day-mortality.(12) but, the reliability of P/F ratio was not equal to A-aDO2 measurement for gas exchange. $\mathrm{P} / \mathrm{F}$ ratio was influenced by $\mathrm{FiO} 2$ and intra-pulmonal shunt fraction. The other factor related to the gas exchange as well as $\mathrm{P} / \mathrm{F}$ ratio were haemoglobin, difference in oxygen concentration within artery and vein, as well as barometric pressure.(13) P/F ratio in non-intubated patients using nasal canula, venturi mask, or reservoir mask with NIV that was connected with high-flow oxygen in CPAP, only could predict a crude estimation. This may be because the Oxygen percentage that was estimated theoretically, actually could be variable according to the patient's ventilation pattern (tidal volume, respiratory frequency, breathing pause) or respiratory leakage the actual $\mathrm{P} / \mathrm{F}$ ratio was commonly lower than the estimation in nonintubated patients.(12)

Patients with mechanical ventilator support and passed away had a lower average of $\mathrm{P} / \mathrm{F}$ ratio compared to those who were survived $(44 \mathrm{mmHg}$ vs $122 \mathrm{mmHg}, \mathrm{p}<0,01)$ and worse response to therapy after 7 days admission. A cohort study including 9.990 COVID-19 patients in ICU in England, P/F ratio within 24 hours was significantly correlated to mortality. Patients with mechanical ventilation and $\mathrm{P} / \mathrm{F}$ ratio of $>300 \mathrm{mmHg}$ had a 1,89 times risk of mortality compared to those whom without mechanical ventilation. For every $50 \mathrm{mmHg}$ decrease of the $\mathrm{P} / \mathrm{F}$ ratio, 30-day mortality was increased to 1,35 times fold in patients without mechanical ventilation and 1,21 times fold in patients with mechanical ventilation.(12) Similar to our study, the cut-off $\mathrm{P} / \mathrm{F}$ ratio at day- 0 was $119 \mathrm{mmHg}$ and $110 \mathrm{mmHg}$ at day- 3 of intensive care admission. Compared to day- 0 and day-3, day-0 cut-off value of $\mathrm{P} / \mathrm{F}$ ratio had a better prediction on the HFNC failure incidence. Compared to the ROX index as the HFNC failure predictor, P/F ratio had a higher sensitivity but less specificity.

\section{Conclusion}

The increasing of D-dimer concentration, decreasing of $\mathrm{P} / \mathrm{F}$ ratio, and decreasing of ROX index were significantly correlated to the HFNC incidence of COVID-19 patients with ARDS.

\section{References}

1. Evans CE. Hypoxia and HIF activation as a possible link between sepsis and thrombosis. Thromb J [Internet]. 2019 Aug 14 [cited 2022 Jan 8];17(1):1-4. Available from: https://thrombosisjournal.biomedcentral.com/articles/10.1186/s12959-019-0205-9

2. Pilli VS, Datta A, Afreen S, Catalano D, Szabo G, Majumder R. Hypoxia downregulates protein S expression. Blood [Internet]. 2018 Jul 26 [cited 2022 Jan 8];132(4):452-5. Available from: http://ashpublications.org/blood/article-pdf/132/4/452/1407115/blood841585.pdf

3. Tang N, Li D, Wang X, Sun Z. Abnormal coagulation parameters are associated with poor prognosis in patients with novel coronavirus pneumonia. J Thromb Haemost. 2020;18(4):844-7.

4. Rawal G, Yadav S, Kumar R. Acute Respiratory Distress Syndrome: An Update and Review. J Transl Intern Med. 2018 Jun;6(2):74-7.

5. Gianstefani A, Farina G, Salvatore V, Alvau F, Artesiani ML, Bonfatti S, et al. Role of ROX index in the first assessment of COVID-19 patients in the emergency department. Intern Emerg Med [Internet]. 2021
Oct
$1 \quad$ [cited
2022 Jan
10];16(7):1959-65.
Available 
https://link.springer.com/article/10.1007/s11739-021-02675-2

6. PDPI, PERKI, PAPDI, PERDATIN, IDAI. Pedoman tatalaksana COVID-19. Burhan E, Susanto AD, Isbaniah F, Nasution SA, Ginanjar E, Pitoyo C wicaksono, et al., editors. Pedoman Tatalaksana COVID19 [Internet]. 2020 [cited 2021 Nov 10];1-138. Available from: https://www.papdi.or.id/download/983pedoman-tatalaksana-covid-19-edisi-3-desember-2020

7. Roca O, Caralt B, Messika J, Samper M, Sztrymf B, Hernández G, et al. An index combining respiratory rate and oxygenation to predict outcome of nasal high-flow therapy. Am J Respir Crit Care Med [Internet]. 2019 May 31 [cited 2022 Jan 10];199(11):1368-76. Available from: www.clinicaltrials.gov

8. Panadero C, Abad-Fernández A, Rio-Ramirez MT, Gutierrez CMA, Calderon-Alcala M, Lopez-Riolobos C, et al. High-flow nasal cannula for Acute Respiratory Distress Syndrome (ARDS) due to COVID-19. Multidiscip Respir Med [Internet]. 2020 Jan 28 [cited 2022 Jan 10];15(1). Available from: https://pubmed.ncbi.nlm.nih.gov/32983456/

9. Lee JY, Kim HA, Huh K, Hyun M, Rhee JY, Jang S, et al. Risk Factors for Mortality and Respiratory Support in Elderly Patients Hospitalized with COVID-19 in Korea. J Korean Med Sci [Internet]. 2020 Jun 2 [cited 2022 Jan 10];35(23). Available from: https://doi.org/10.3346/jkms.2020.35.e223

10. Kumar A, Arora A, Sharma P, Anikhindi SA, Bansal N, Singla V, et al. Is diabetes mellitus associated with mortality and severity of COVID-19? A meta-analysis. Diabetes Metab Syndr [Internet]. 2020 Jul 1 [cited 2022 Jan 10];14(4):535. Available from: /pmc/articles/PMC7200339/

11. Aggarwal A, Arora U, Mittal A, Aggarwal A, Singh K, Ray A, et al. Use of HFNC in COVID-19 patients in non-ICU setting: Experience from a tertiary referral centre of north India and a systematic review of literature. [cited 2022 Jan 10]; Available from: https://doi.org/10.1101/2021.06.23.21259045

12. Ferrando-Vivas P, Doidge J, Thomas K, Gould DW, Mouncey P, Shankar-Hari M, et al. Prognostic Factors for 30-Day Mortality in Critically Ill Patients With Coronavirus Disease 2019: An Observational Cohort Study. Crit Care Med [Internet]. 2021 [cited 2022 Jan 10];49(1):102-11. Available from: https://pubmed.ncbi.nlm.nih.gov/33116052/

13. Pisano A, Yavorovskiy A, Verniero L, Landoni G. Indications for Tracheal Intubation in Patients With Coronavirus Disease 2019 (COVID-19). J Cardiothorac Vasc Anesth [Internet]. 2021 May 1 [cited 2022 Jan 10];35(5):1276-80. Available from: https://pubmed.ncbi.nlm.nih.gov/33349501/ 